\title{
Giant endometrial polyp protruding from the external cervical os in a postmenopausal woman: magnetic resonance imaging and hysteroscopic findings
}

\author{
Ahmet Said Çil, ${ }^{1}$ Murat Bozkurt, ${ }^{2}$ Duygu Kara, ${ }^{3}$ Beril Guler ${ }^{4}$ \\ Keywords: Giant endometrial polyps, hysteroscopic polyp excision, hysteroscopic surgical \\ procedures, MRI
}

\begin{abstract}
Endometrial polyps are most commonly seen in the postmenopausal women with uterine bleeding, although the giant polyps which originate from the uterine cavity and protruding from the cervical os are rare. Several cases which have been described in the literature are usually developed secondary to tamoxifen use, and the polyps do not extend or protrude from the external cervical os. Most of the polyps protruded from the cervical os can mimic a cervical neoplasia or endocervical polyp. We report the case of a giant endometrial polyp ( $8 \times 4 \times 3 \mathrm{~cm}$ in size) which was protruding from the external cervical os and that developed spontaneously without tamoxifen use in a multiparous 73 -year-old woman presenting with vaginal bleeding. Hysteroscopic polypectomy was performed and no recurrence was seen at 6 months after surgery. Diagnosis, management and outcome of this rare entity have been discussed according to the literature.

${ }^{1}$ Department of Radiology, Universal Hospitals Group, Malatya, Turkey

${ }^{2}$ Department of Obstetrics and Gynecology, Universal Hospitals Group, Malatya, Turkey

${ }^{3}$ Department of Radiology, Sevgi Hospital, Malatya, Turkey

${ }^{4}$ Department of Pathology, Bezmi Alem University, Istanbul, Turkey
\end{abstract}

\section{Introduction}

Endometrial polyps are localized overgrowths of endometrial tissue composed of variable amount of glands, stroma, and blood vessels covered by epithelium. Endometrial polyps are a common cause of vaginal bleeding in pre- and postmenopausal women. 1 The most common size is less than $2 \mathrm{~cm}$, and polyps greater than $4 \mathrm{~cm}$ are called giant polyps. $^{2}$ Endometrial polyps are most frequently seen in multiparous women in the fifth decade. Endometrial polyp removal is generally performed by ambulatory hysteroscopic polypectomy. ${ }^{2,3}$ Giant polyps usually occur secondary to high estrogen levels or tamoxifen therapy after breast cancer., ${ }^{4,5}$ Rising polyps usually originate from the endocervix and are called endocervical polyps. ${ }^{2}$ Although giant endometrial polyps, which fill the endometrial cavity, or protruding endocervical polyps with a size greater than $4 \mathrm{~cm}$ are published in several cases, endometrial giant polyp

Please cite this paper as: Çil AS, Bozkurt M, Kara D, Guler B. Giant endometrial polyp protruding from the external cervical os in a postmenopausal woman: magnetic resonance imaging and hysteroscopic findings. Proc Obstet Gynecol. 2013;3(3): Article 2 [ 9 p.]. Available from: http://ir.uiowa.edu/pog/. Free full text article.

Corresponding author: Murat Bozkurt, Universal Malatya Hastanesi, Turgut Ozal Bulvari Ankara Asfalti 6.km No:216 44000 Malatya/Turkey. Telephone 904222382828/1546. Fax: 904222382600.jindrmb@yahoo.com.

Financial Disclosure: The authors report no conflict of interest.

Copyright: @ 2013 Çil et al. This is an open-access article distributed under the terms of the Creative Commons Attribution License, which permits unrestricted use, distribution, and reproduction in any medium, provided the original author and source are credited. 
rising to the cervix are very rare. ${ }^{5}$ In this report, we describe the case of a giant $8 \times 4 \times 3 \mathrm{~cm}$ endometrial polyp originating from the posterior wall of the uterine cavity that extended to the external cervical os and protruded into the vagina. The clinical, radiological, hysteroscopic and histopathologic data of this entity have been discussed according to the literature.

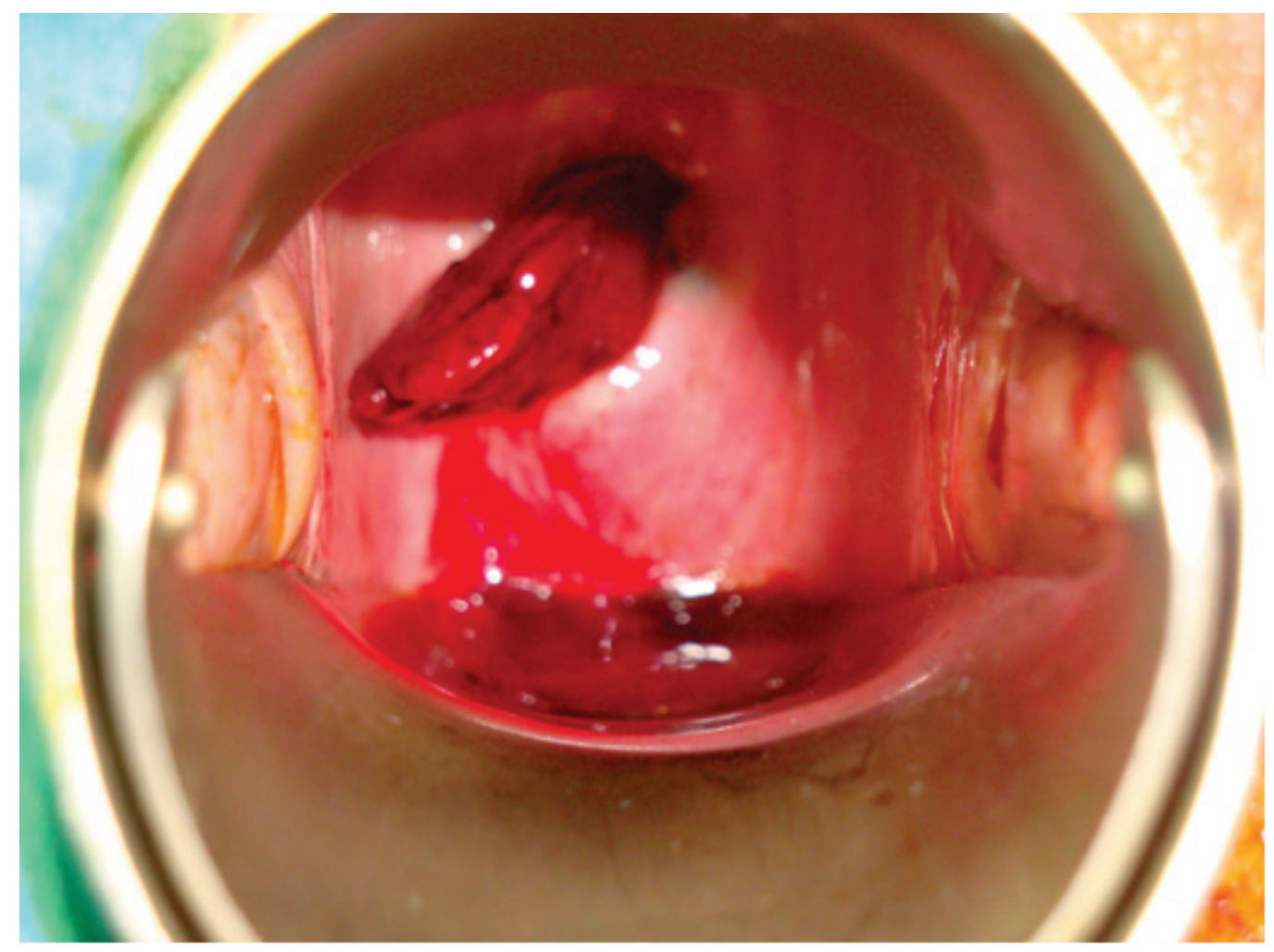

Figure 1: On the vaginal examination, a vascularized, hemorrhagic mass protruding from the external cervical os was seen.

\section{Case Report}

A 73-year-old woman, gravida 8, para 6 , presented to our clinic with abnormal vaginal bleeding. The patient described intermittent postmenopausal vaginal bleeding. On clinical examination, a painless mass was palpated intra vaginally. On vaginal specular examination, a vascularized, hemorrhagic mass protruding from the external cervical os was seen (Figure 1). The mass bled easily upon contact. Transvaginal sonography revealed endometrial thicknesses of $28 \mathrm{~mm}$, which did not correlate with patient age. The clinical findings and transvaginal sonographic examination suggested an endometrial or cervical carcinoma. Pelvic MRI showed an intracavitary mass with homogenous low signal intensity on T1-weighted images and smooth margins on high signal intensity on T2-weighted images. After contrast media (GdDTPA) injection, the enhancement pattern was homogenous and less than the adjacent myometrium. The junctional zone was intact and there was no myometrial invasion (Figure 3 ). 

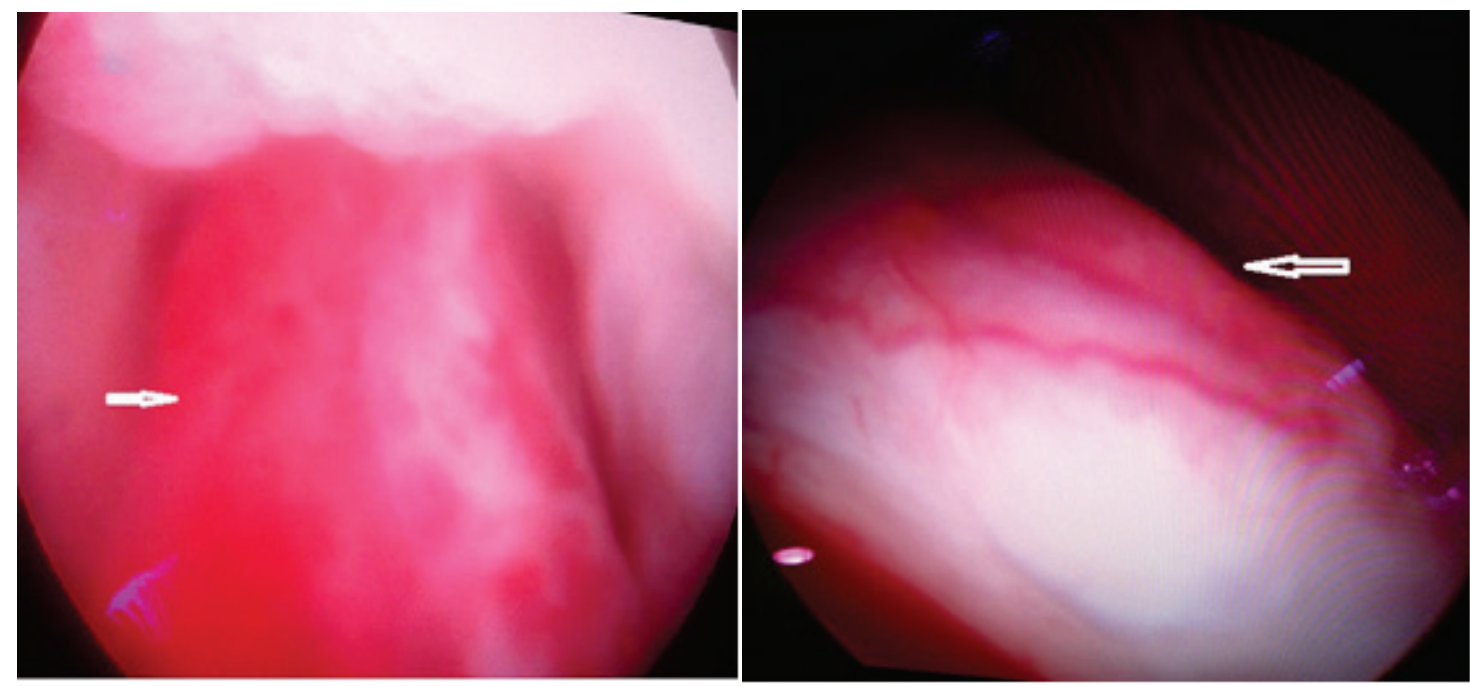

Figure 2: Hysteroscopic examination showed a mass originating from the posterior wall of uterine cavity that extended to the external cervical os and protruded into the vagina.

Hysteroscopy was performed with a 10-mm Storz resectoscope (Karl Storz, Tuttingen, Germany). The uterine cavity was distended with a solution of mannitol with a pressure of $75 \mathrm{~mm}-\mathrm{Hg}$. The hysteroscopic examination showed that the mass originated from the posterior wall of uterine cavity, extended to the external cervical os and protruded into the vagina (Figure 2). The polyp was completely removed with the bipolar cutting loop, and then the base of the lesion was cauterized with a roller ball. After removal of the polyp, the uterine cavity was normal. The patient was discharged 8 hours after the operation. The postoperative follow-up interval was unremarkable and the patient did not describe any vaginal bleeding. The pathological diagnosis was confirmed to be a giant endometrial polyp with a size of $8 \times 3$ $\mathrm{cm}$ (Figure 4). Microscopically, the tumor was composed of multiple endometrial glands embedded in the stroma. No nuclear or cytological atypia were noted and the mitotic index remained low with 1 mitose/10 HPF (high power field) (Figure 5). No sign of dysplasia or neoplasia were observed in the glandular or metaplastic epithelium. At six month follow-up, there was no recurrence seen by vaginal examination or imaging modalities.

\section{Discussion}

Endometrial polyps are divided into three basic groups according to their response to ovarian hormones. These types include mature functioning polyps, immature non-functioning polyps and non-functioning adenomyomatous polyps. ${ }^{2}$ In this case report, the histopathologic examination confirmed an immature non-functioning polyp. 


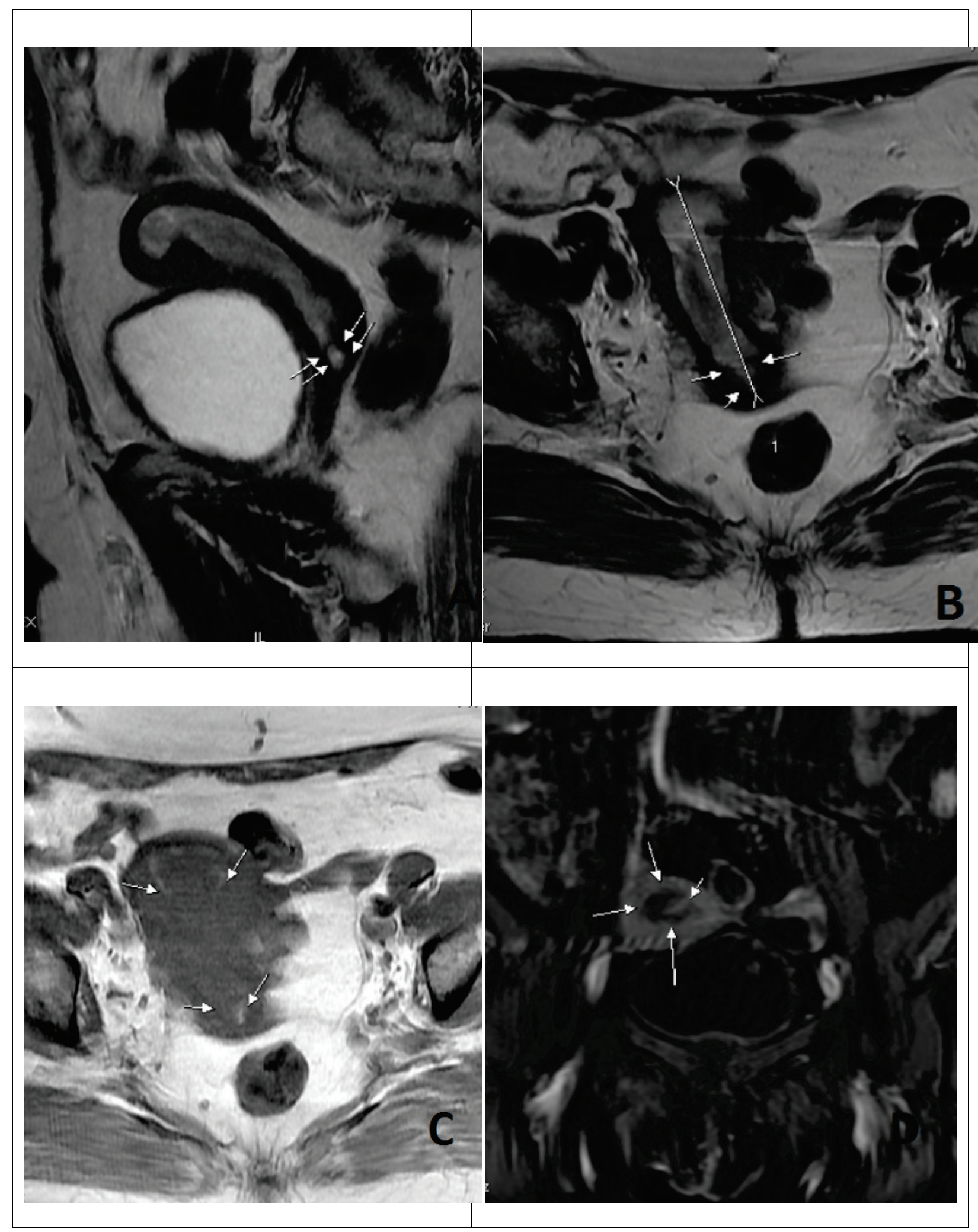

Figure 3: Pelvic MRI was showed that an $8 \times 4 \times 3 \mathrm{~cm}$ intracavitary mass with homogenous high signal intensity on T2-weighted images with smooth margins (A, B) and low signal intensity on T1 weighted images (C). After the contrast media (Gd-DTPA) injection, the enhancement pattern was homogenous and less than the adjacent myometrium (D). 
Table 1: Features of published giant polyps.

\begin{tabular}{|l|l|l|l|l|}
\hline Author & Size $(\mathrm{cm})$ & Origin & $\begin{array}{l}\text { Tamoxifen } \\
\text { treatment }\end{array}$ & $\begin{array}{l}\text { Cervical } \\
\text { protrusion }\end{array}$ \\
\hline Nomikos et al $^{4 .}$ & 8 & Uterus & + & - \\
\hline Moon et al. $^{5}$ & 7 & Uterus & + & - \\
\hline Arıdoğan et al. $^{7}$ & 14 & Cervix & - & + \\
\hline Amesse et al. $^{8}$ & 5.2 & Cervix & - & + \\
\hline Adinma et al. $^{9}$ & 5 & Cervix & - & + \\
\hline Branger et al. $^{10}$ & 15 & Cervix & - & + \\
\hline Bucella et al. $^{11}$ & 5.5 & Cervix & - & + \\
\hline Duckmann et al. $^{12}$ & 10 & Cervix & - & + \\
\hline Gögüs et al. $^{13}$ & 5 & Cervix & - & + \\
\hline Khalil et al. $^{14}$ & 17 & Cervix & - & + \\
\hline Lippert et al. $^{15}$ & 17 & Cervix & - & + \\
\hline Sairer et al. $^{16}$ & 8 & Cervix & - & + \\
\hline Çil et al. $^{17}$ & 13 & Uterus & - & + \\
\hline
\end{tabular}

Table 1

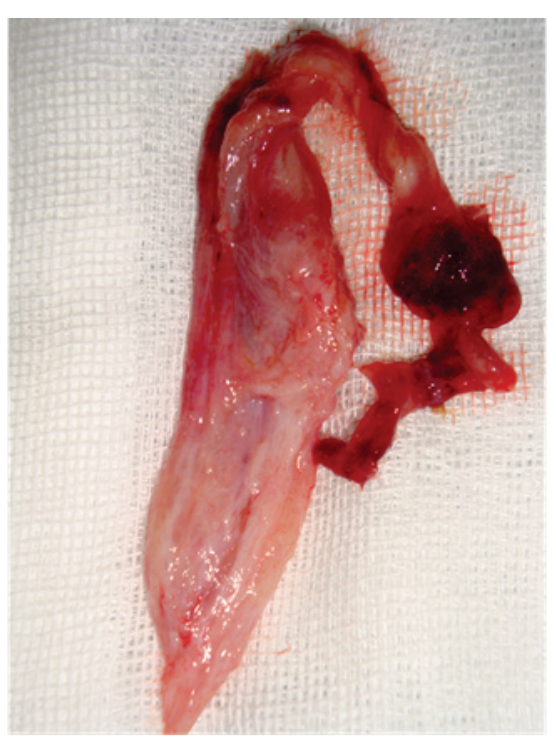

Figure 4: Macroscopic appearance of the giant polyp measuring $8 \times 3 \mathrm{~cm}$ in diameter.

In the literature, most giant polyps protruding from the external cervical os originated from the cervix and are called endocervical polyps. Other giant polyps which originate from the endometrium but are contained within the uterine cavity are called endometrial polys. Interestingly in our case report, the polyp originated in the uterine cavity, extended into the cervix and protruded into the external cervical os. Postmenopausal uterine bleeding (PMB) is a common complaint in general gynecologic practice. The common cause of this symptom in postmenopausal women is atrophic endometrium $(32.2 \%)$. The other important potential cause of $\mathrm{PMB}$ is endometrial cancer (10\%). The exclusion of endometrial hyperplasia and carcinoma is required in the evaluation of patients with abnormal 
uterine bleeding.

Polyps (24.3\%) are the other cause of the PMB. ${ }^{6}$ Polyps greater than $4 \mathrm{~cm}$ are called giant polyps, and most giant endometrial polyps described in the literature were associated with postmenopausal tamoxifen treatment. ${ }^{4,5}$ Hormonal factors may be involved in abnormal uterine bleeding as indicated by endometrial abnormalities in patients treated with tamoxifen. Despite being an estrogen antagonist, tamoxifen has been shown to have estrogen agonistic effects on the endometrium. The partial agonistic activity of tamoxifen in postmenopausal women may produce a hormonal environment of low levels of unopposed estrogen similar to that in perimenopausal woman. In our patient, the polyp developed spontaneously as the patient did not use tamoxifen or other drugs like hormone replacement treatment (Table 1).

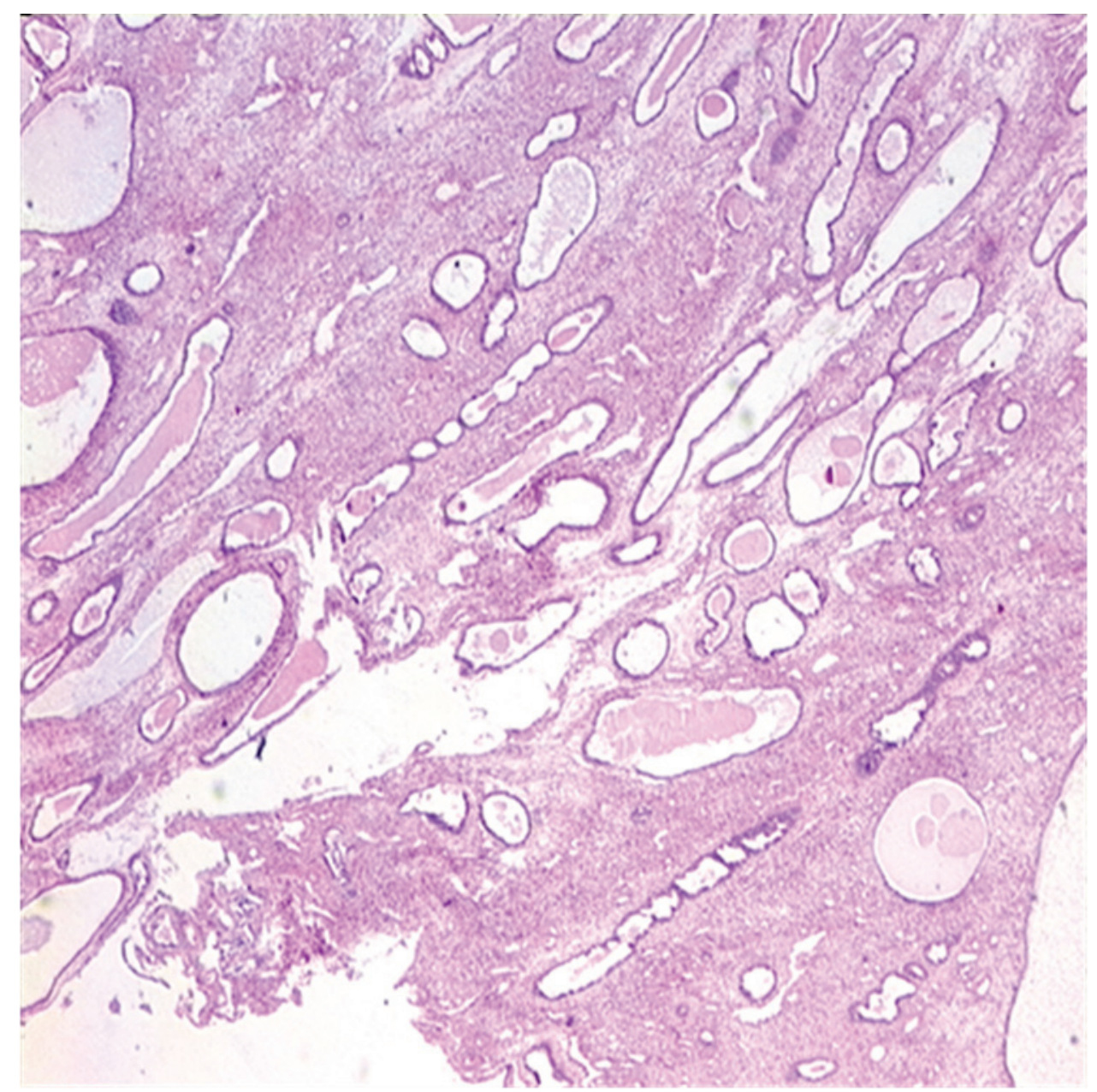

Figure 5: Multiple atrophic endometrial glands embedded in the fibrotic stroma, including a single row of prismatic or cubic epithelium with thick-walled blood vessels (H\&E 40x100). 
Noninvasive techniques such as transvaginal ultrasonography, with or without the use of 3-dimensional ultrasonography and contrast techniques, remain first-line. In postmenopausal uterine bleeding, transvaginal ultrasonography is a routine, non-invasive component of investigation. In the sonographic examination, 28-mm-thick endometrium was seen in our case. The clinical findings and transvaginal sonographic examination suggested an endometrial or cervical carcinoma. Therefore, we utilized the advanced radiologic modalities such as MRI. Two different MRI appearances have been described for endometrial polyps. Most of the MRI studies in patients with tamoxifen use revealed a heterogenous cystic endometrial mass which was hyperintense as compared to the adjacent myometrium on T2weighted images. After gadolinium injection, the mass may be slightly enhanced or not enhance. The second appearance was homogeneous intermediate to high signal intensity on T2-weighted images. The cystic component was not seen in the MRI examination and was not enhanced after contrast media injection. In our case, the polyp has homogenously hyperintense on T2 weighted images and not enhance after contrast media injection. On MRI examination, the distinction between the early noninvasive endometrial carcinoma from the endometrial polyp and hyperplasia are difficult to distinguish. The appearance of a normal junctional zone by MRI may help to distinguish between malignant vs. benign endometrial pathologies and myometrial invasion. Also, the contrast enhanced $\mathrm{MRI}$ is the most accurate technique for evaluating the presence and the depth of myometrial invasion of endometrial carcinoma. ${ }^{18}$
On the vaginal examination, a vascularized, hemorrhagic mass protruded from the external cervical os was seen. The mass bled easily upon contact. Although there was a lack of cervical invasion, the morphologic appearance of the lesion initially suggested cervical cancer. Histopathological examination must be performed on all resected polyps to rule out endometrial polyps (0.5-3\%) with malignant foci. ${ }^{2}$ The differential diagnosis of the protruding polyps from the external cervical os includes malignant pathologies such as cervical cancer, cervical embryonal rhabdomyosarcoma, mullerian adenosarcoma, endocervical or endometrial adenosarcoma and cervical lymphoma. ${ }^{11,19,20}$

For the treatment and histologic diagnosis of endometrial polyps, hysteroscopic resection is the most effective method, while blind biopsy and curettage have low diagnostic accuracy and should not be performed.

In summary, we report the case of a giant endometrial polyp originating in the posterior uterine wall which protruded through the cervix in a postmenopausal woman. In this case report, neither tamoxifen nor HRT was used. Although the MRI and hysteroscopic examination are helpful in the differential diagnosis of the polyps, the definitive diagnosis was confirmed by histopathologic evaluation.

\section{References}

1. Jutras ML, Cowan BD. Abnormal bleeding in the climacteric. Obstet Gynecol Clin North Am. 1990 Jun;17(2):409-25. PubMed PMID: 2234751 . 
2. Peterson WF, Novak ER. Endometrial polyps. Obstet Gynecol. 1956 Jul;8(1):40-9. PubMed PMID: 13335063.

3. Golan A, Ber A, Wolman I, David MP. Cervical polyp: evaluation of current treatment. Gynecol Obstet Invest. 1994;37(1):56-8. PubMed PMID: 8125411.

http://dx.doi.org/10.1159/000292522

4. Nomikos IN, Elemenoglou J, Papatheophanis J. Tamoxifen-induced endometrial polyp. A case report and review of the literature. Eur $\mathrm{J}$ Gynaecol Oncol. 1998;19(5):476-8. PubMed PMID: 9863916

5. Moon SH, Lee SE, Jung IK, Jeong JE, Park WY, Yi WH, Suh DS, Yoon MS, $\mathrm{Kim} \mathrm{KH}$. A giant endometrial polyp with tamoxifen therapy in postmenopausal woman. Korean J Obstet Gynecol. 2011; 54(12):836840.

http://dx.doi.org/10.5468/KJOG.2011.5 4.12 .836

6. Bergamo AM, Depes DD, Pereira AM, Santana TC, Lippi UG, Lopes RG. Hysteroscopic endometrial polypectomy: outpatient versus conventional treatment. Einstein (Sao Paulo). 2012 Sep;10(3):323-328. . PubMed PMID: 23386012. http://dx.doi.org/10.1590/S167945082012000300012

7. Aridogan N, Cetin MT, Kadayifci $\mathrm{O}$, Atay Y, Bisak U. Giant cervical polyp due to a foreign body in a 'virgin'. Aust N Z J Obstet Gynaecol. 1988 May;28(2):146-7. PubMed PMID: 3228410.

http://dx.doi.org/10.1111/j.1479828X.1988.tb01646.x

8. Amesse LS, Taneja A, Broxson E, Pfaff-Amesse T. Protruding giant cervical polyp in a young adolescent with a previous rhabdomyosarcoma. $\mathrm{J}$ Pediatr Adolesc Gynecol. 2002 Dec;15(5):271-7. PubMed PMID: 12547657.
9. Adinma JI. Cervical polyp presenting as inevitable abortion. Trop Doct. 1989 Oct:19(4):181. PubMed PMID: 2815311.

10. Branger C, Dreher E, Burkhardt A, Schmuckle U. [Giant polyp of the cervix]. Geburtshilfe Frauenheilkd. 1991 Feb;51(2):148-9. German. PubMed PMID: 2040412.

11. Bucella D, Frédéric $B$, Noël JC. Giant cervical polyp: a case report and review of a rare entity. Arch Gynecol Obstet. 2008 Sep;278(3):295-8. doi: 10.1007/s00404-008-0575-x. Epub 2008 Jan 31. PubMed PMID: 18236053.

12. Duckman S, Suarez JR, Sese LQ. Giant cervical polyp. Am J Obstet Gynecol. $1988 \quad$ Oct;159(4):852-4. PubMed PM

13. Gögüs $S$, Senocak ME, Arda IS, Büyükpamukçu N, Akçören $Z$. Multiocularendocervical polyp in a fiveyear-old girl. Pediatr Pathol. 1993 JulAug;13(4):415-9. PubMed PMID: 8372026.ID: 3177535. http://dx.doi.org/10.3109/15513819309 048230

14. Khalil AM, Azar GB, Kaspar HG, AbuMusa AA, Chararah IR, Seoud MA. Giant cervical polyp. A case report. J Reprod Med. 1996 Aug;41(8):619-21. PubMed PMID: 8866393.

15. Lippert LJ, Richart RM, Ferenczy A. Giant benign endocervical polyp: report of a case. Am J Obstet Gynecol. 1974 Apr 15;118(8):1140-1. PubMed PMID: 4817652.

16. Saier FL, Hovadhanakul P, Ostapowicz F. Giant cervical polyp. Obstet Gynecol. 1973 Jan;41(1):94-6. PubMed PMID: 4682621. 
17. Karabacakoglu A, Karakose S, Cil AS, Kaya A. Contrast media-enhanced power Doppler sonography for evaluation of hemangiomas and malignant tumors in the liver. $\mathrm{J}$ Gastroenterol Hepatol. 2003 Jan;18(1):92-8. PubMed PMID: 12519230.

http://dx.doi.org/10.1046/j.14401746.2003.02900.x

18. Grasel RP, Outwater EK, Siegelman ES, Capuzzi D, Parker L, Hussain SM. Endometrial polyps: MR imaging features and distinction from endometrial carcinoma. Radiology. 2000 Jan;214(1):47-52. PubMed PMID: 10644100.
19. Ma J, Shi QL, Zhou XJ, Meng K, Chen JY, Huang WB. Lymphoma-like lesion of the uterine cervix: report of 12 cases of a rare entity. Int $\mathrm{J}$ Gynecol Pathol. 2007 Apr;26(2):194-8. PubMed PMID: 17413989.

http://dx.doi.org/10.1097/01.pgp.00002 28144.59677.5a

20. Kerner $H$, Lichtig C. Müllerian adenosarcoma presenting as cervical polyps: a report of seven cases and review of the literature. Obstet Gynecol. 1993 May;81(5 ( Pt 1)):6559. PubMed PMID: 8385764. 